\title{
Amniotic Membrane-Coated Polypropylene Mesh for the Repair of Incisional Hernia: An Experimental Study In a Rat Model of Abdominal Wall Defect
}

\author{
Sinan Soylu, ${ }^{1,}$ Caglar Yildiz, ${ }^{2}$ Birkan Bozkurt, ${ }^{1}$ Savas Karakus, ${ }^{2}$ Begum Kurt, ${ }^{3}$ and Atilla Kurt $^{2}$ \\ ${ }^{1}$ Department of General Surgery, Cumhuriyet University Faculty of Medicine, Sivas, Turkey \\ ${ }^{2}$ Department of Gynecology and Obstetrics, Cumhuriyet University Faculty of Medicine, Sivas, Turkey \\ ${ }^{3}$ Clinics of Gynecology and Obstetrics, Sivas State Hospital, Sivas, Turkey \\ "Corresponding author: Sinan Soylu, Department of General Surgery Cumhuriyet University Faculty of Medicine, Sivas, Turkey. Tel: +90-3462580450, Fax: +90-3462191110, \\ E-mail: soylu.sinan@hotmail.com
}

Received 2017 October 12; Revised 2017 November 14; Accepted 2018 February 07.

\begin{abstract}
Background: Incisional hernia repairs are among common abdominal wall surgeries, can be primarily required or being reconstructed using a synthetic or biological material.

Objectives: This study aimed at evaluating intra-abdominal adhesions and incisional site healing after the repair of the abdominal wall by fresh amniotic membrane-coated polypropylene mesh in comparison to only polypropylene mesh in an experimental rat study.

Methods: The study protocol was approved by the Cumhuriyet University Institutional Ethics Committee for Animal Experiments (Sivas-Turkiye, date 24/06/2015). Sixteen pregnant female Wistar-Albino rats (mean weight, $275 \mathrm{~g}$ ) were anesthetized on the 21st day of pregnancy, and a 1-cm area of the abdominal wall was excised. The pregnancy was terminated, emerging amniotic membranes were dissected, and eight pieces of the 1- $\mathrm{cm}^{2}$ polypropylene mesh were coated with these amniotic membranes without using any suture or adhesive. The polypropylene meshes were sutured on the abdominal wall of eight rats (control group), selected by simple random sampling. For the remaining eight rats, the same procedure was applied with the amniotic membrane-coated polypropylene meshes (experimental group). On the 28th postoperative day, the anterior abdominal wall was opened, and intra-abdominal adhesions were assessed macroscopically by Nair's adhesion scoring system. Strip-shaped biopsy samples were taken from incision lines for histopathological examination.

Results: The experimental group had significantly less intra-abdominal adhesions (i.e., Nair's score of 2 to 4 ) compared to the control group (two and six rats, respectively; $\mathrm{P}=0.046$ ), and had significantly lower mean score for polymorphonuclear leukocyte infiltration $(\mathrm{P}=0.039)$, hyperemia $(\mathrm{P}=0.039)$, and epithelialization $(\mathrm{P}=0.039)$. The score for the increase in connective tissue $(\mathrm{P}=0.018)$ was significantly higher in the experimental group, and the scores for edema $(\mathrm{P}=0.590)$ and macrophage infiltration $(\mathrm{P}=0.590)$ were similar between the two groups.

Conclusions: The use of polypropylene mesh coated with fresh amniotic membrane provides the advantage of decreasing postoperative intra-abdominal adhesions along with less inflammation and higher epithelialization after abdominal wall repair surgery.
\end{abstract}

Keywords: Amnion, Incisional Hernia, Surgical Mesh, Rats

\section{Background}

Incisional hernias are a common problem encountered by $5 \%$ to $15 \%$ of abdominal wall surgeries $(1,2)$. It causes chronic pain, ileus, fistula, and creates obstacles for re-operation. Although an incisional hernia can be primarily repaired by using its fascia, in cases where the defect is not significant, reconstruction with a synthetic or biological material (graft) is needed when the primary tissue is not sufficient $(3,4)$. Currently, the most commonly used synthetic material for the treatment of the incisional hernias and the repair of abdominal wall defects is polypropylene mesh.
Adhesions and recurrences are common complications of abdominal wall reconstruction with a synthetic material (5). Particularly in cases with large tissue loss, polypropylene mesh comes in contact with the intraabdominal tissues, causing the adhesions, and leading to intestinal obstruction or fistulas (6). Although many alternative materials and methods for repair of abdominal wall defects were suggested in the literature, such as the use of omentum, peritoneum, biological materials, chemicals, stretch films, etc., the ideal material for preventing intraabdominal adhesions is yet to be defined (7-14).

The Amniotic Membrane (AM), innermost layer of placenta, is an avascular matrix with a basement membrane

Copyright (c) 2018, Iranian Red Crescent Medical Journal. This is an open-access article distributed under the terms of the Creative Commons Attribution-NonCommercial 4.0 International License (http://creativecommons.org/licenses/by-nc/4.0/) which permits copy and redistribute the material just in noncommercial usages, provided the original work is properly cited 
and a monolayer of epithelial cells without major histocompatibility complex antigens (6). It has been known that AM, can be used for reconstruction of various tissues (15-18). Amniotic Membrane induces fibrosis, epithelization, and neovascularization. It also has antiviral and antimicrobial effects, and decreases inflammation $(6,19$, 20). Therefore, it can be used as an anti-adherent layer for polypropylene mesh in repair of abdominal wall defects.

Amniotic Membrane transplantation was used in many studies with tissue preserved by cryopreservation or in glycerol solution (16). Multiple authors have described the use of fresh human AM for transplantation in vaginal prolapsed repairs without serious complications $(16,21,22)$ In the direction of these studies; the current researchers intended to use fresh allograft AM-Coated Polypropylene Mesh (AM-CPM) in rats.

\section{Objectives}

The objective of this study was to describe a simple, novel, inexpensive, and effective surgical technique for incisional hernia repair. The authors aimed at evaluating intra-abdominal adhesions and healing process at the incision site after the repair of abdominal wall, by using fresh AM-CPM in comparison to only polypropylene mesh in an experimental rat study.

\section{Methods}

Sixteen pregnant Wistar-Albino rats weighing 200 to $250 \mathrm{~g}$ (mean weight of $225 \mathrm{~g}$ ) were included in the study. They were provided by Cumhuriyet University School of Medicine Animal Laboratory Sivas, Turkey. The study protocol was approved by Cumhuriyet University Institutional Ethics Committee for Animal Experiments (Sivas-Turkiye, date 24/06/2015; code: 65202830-050.04.04/50). All of the investigations conformed to the 1996 National Academy of Science's Guide for the Care and Use of Laboratory Animals.

\subsection{Study Design}

Rats were kept in cages under 21 to $23^{\circ} \mathrm{C}$ room temperature with a 12/12-hour light/dark cycle and fed standard chow and water ad libitum. Simple randomization was used. Rats were divided to two groups, Group A and Group $B$, each with eight rats (Figure 1). Rats reaching the 21st day of pregnancy were anesthetized by subcutaneous injection of ketamine (90 mg/kg; Ketalar ${ }^{\circledR}$; Parke-Davis, Istanbul, Turkey) and xylazine (3 mg/kg Rhompun ${ }^{\circledR}$; Bayer, Istanbul, Turkey). Afterwards, a full-thickness excision of $1-\mathrm{cm}^{2}$ area of the midline abdominal wall was performed under sterile conditions.
3.2. Preparation for Fresh Amniotic Membrane-Coated Polypropylene Mesh

The pregnancy was terminated, emerging AM was dissected, and washed with $\mathrm{SF}(0.09 \% \mathrm{NaCl})$, and eight pieces of the $1-\mathrm{cm}^{2}$ polypropylene mesh, cut under sterile conditions, were coated with these AM without using any suture or adhesive.

\subsection{Surgical Technique}

The polypropylene meshes were sutured on the anterior abdominal wall of eight randomly selected rats with the Onlay technique using interrupted absorbable polyglactin (Vicryl ${ }^{\circledR}$ 5/0; Sutures Limited UK, Wrexham, UK), and the incision was closed (Group A, control group). For the remaining eight rats, the same procedure was applied with the allograft AM-CPM (Group B, experimental group). Standard postoperative analgesia, anti-biotherapy, and feeding was given to all rats.

\subsection{Adhesion Scoring}

All of the rats were sacrificed by applying intra-cardiac thiopental (Pentothal ${ }^{\circledR} 100 \mathrm{mg} / \mathrm{kg}$ Abbott Laboratories, Istanbul, Turkey) on the 28th post-operative day. The anterior abdominal wall was opened by subcostal incision extending down on both sides. An investigator blinded to the study groups assessed intra-abdominal adhesions macroscopically by Nair's adhesion scoring system (Table 1), (19).

\subsection{Histopathological Examination}

Strip-shaped biopsy samples, taken from incision lines, were fixed by $10 \%$ formaldehyde and prepared in paraffin blocks. Paraffin blocks were stained with hematoxylin and eosin ( $\mathrm{H} \& \mathrm{E}$ ) for histopathological examination. According to edema, hyperemia, infiltration of Polymorphonuclear Leukocytes (PMNL) and macrophages, increase in connective tissue, and epithelialization degree on microscopic evaluation, wound healing was scored between zero and three, where zero indicated absent, one mild, two moderate, and three intense wound healing. Pathologic evaluation was performed by the same pathologist, who was blinded to the study groups.

\subsection{Statistical Analysis}

The study data were binomial except the variable "increase in connective tissue"; thus Cramer's v statistics were utilized in the chi-square analysis. For the frequency distribution Nair's scoring groups, chi-square analysis could not be performed. To overcome this problem, level of adhesion was categorized into two groups; including no or mild adhesion (scores zero to one) and moderate to severe adhesion (scores two to four). 

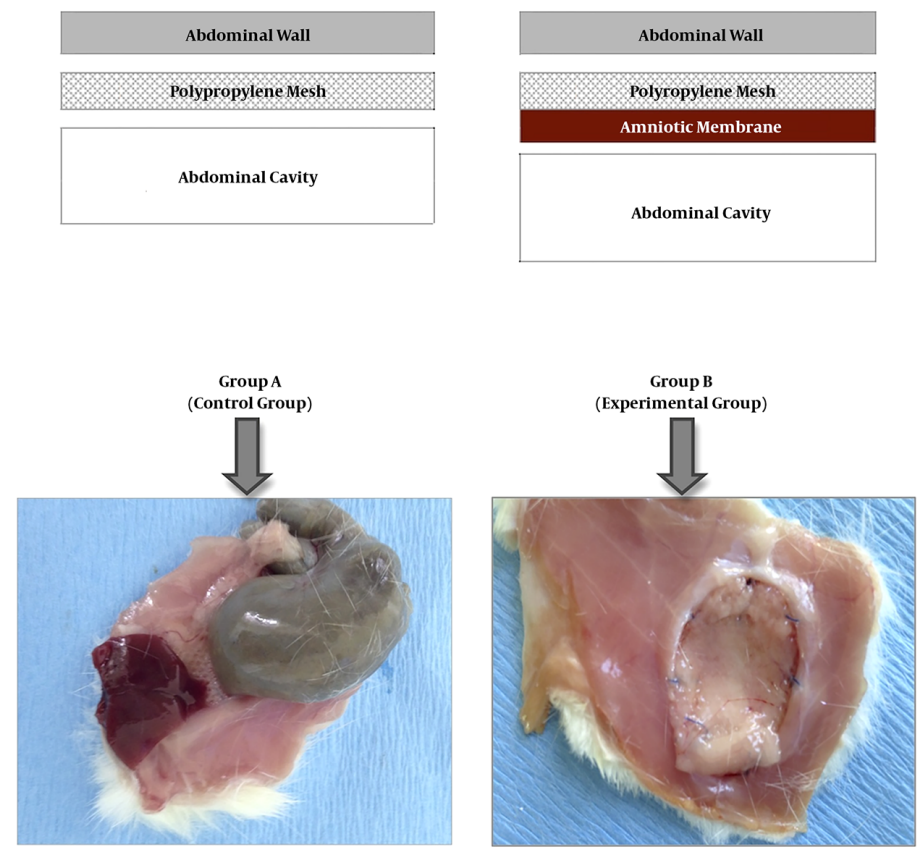

Figure 1. Schematic diagram of study groups (above) and sample images of abdominal graft for each group (below).
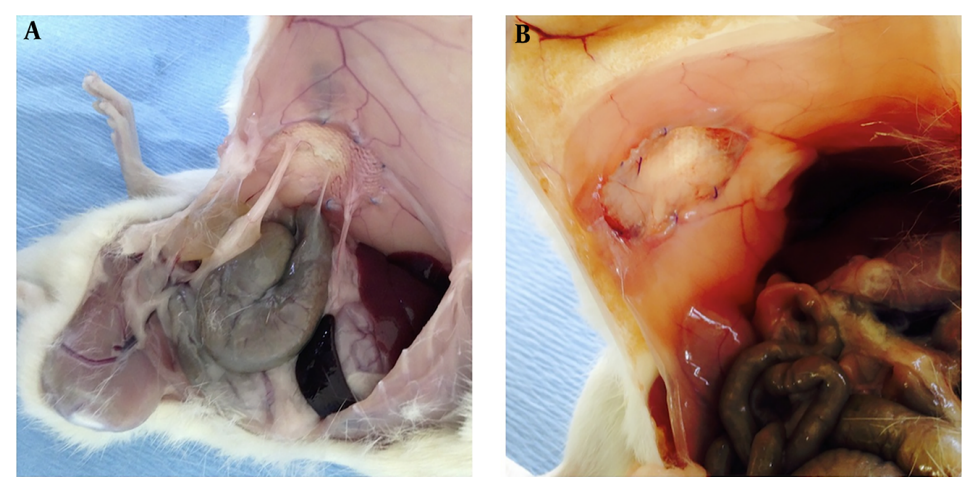

Figure 2. Macroscopic evaluation of intra-abdominal adhesions at postoperative 28th day by an investigator blinded to the study groups. Note that there are remarkable adhesions in experimental group (A), but none in control group (B) in the above example.

Wound healing data, according to edema, hyperemia, infiltration of Polymorphonuclear Leukocytes (PMNL) and macrophages, increase in connective tissue, and epithelialization degree on microscopic evaluation was evaluated with the Whitney-U test, to determine differences between groups.

Statistical analysis was performed by using the IBM SPSS statistics for Windows, version 23.0 (IBM Corp. Armonk, N.Y., USA). The results were presented with $95 \%$ confidence interval. Statistical level of significance was set at $P$
$<0.05$.

\section{Results}

The experimental group (Group B), for which the AMCPM was applied, had significantly less intra-abdominal adhesions compared to the control group (Group A), according to Nair's scoring system $(\mathrm{P}<0.05)$ (Table 2 and Figure 2). The adhesions were observed between the mesh and liver, intestine, and colon. There were no adhesions in the amnion group. 


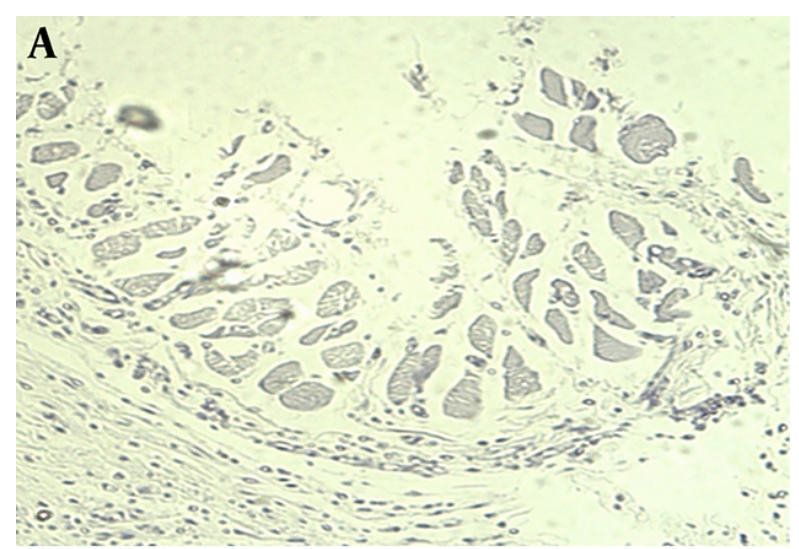

ally lower in the experimental group (Group B), (Figure 3). Histopathological scoring had significantly lower mean score for polymorphonuclear leukocyte infiltration (desc. $A=1.63 \pm 0.52$; desc. $\mathrm{B}=1.13 \pm 0.35 ; \mathrm{P}=0.039$ ), hyperemia (desc. $A=1.63 \pm 0.52 ;$ desc. $B=1.13 \pm 0.35 ; P=0.039)$, and epithelialization (desc. $A=1.13 \pm 0.35$; desc. $B=1.63 \pm$ $0.52 ; \mathrm{P}=0.039$ ). The score for increase in connective tissue (desc. $A=2.63 \pm 0.52 ;$ desc. $\mathrm{B}=1.75 \pm 0.46 ; \mathrm{P}=0.018$ ) was significantly higher in the experimental group, and the scores for edema (desc. $\mathrm{A}=0.38 \pm 0.52$; desc. $\mathrm{B}=0.25 \pm 0.46 ; \mathrm{P}=$ 0.590 ) and macrophage infiltration (desc. $A=1.25 \pm 0.46$; desc. $\mathrm{B}=1.38 \pm 0.52 ; \mathrm{P}=0.590$ ) were similar between groups (Table 3).

Accordingly, the experimental group (Group B) had sig-
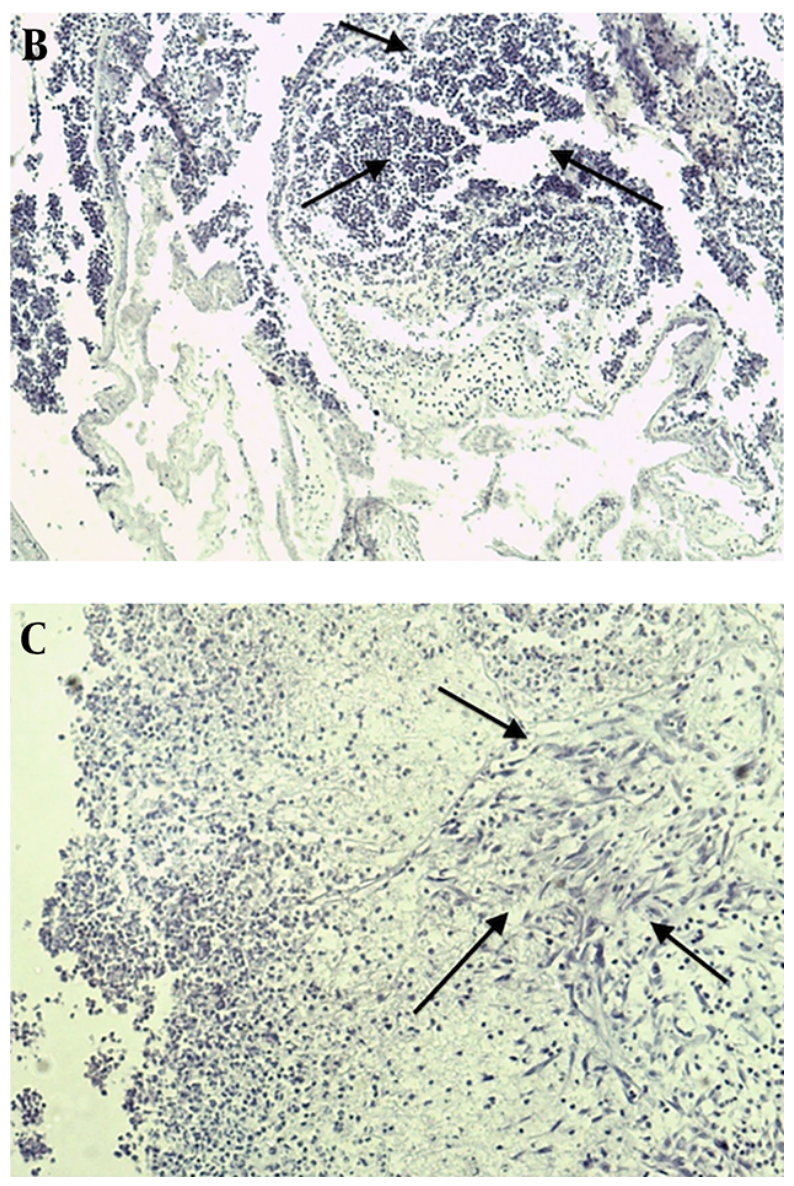

Figure 3. Histopathological images of biopsy samples obtained from abdominal incision lines of experimental group in which the amniotic membrane-coated polypropylene mesh was applied at postoperative 28th day (A) (X200, HematoxylinEosin). The PMNL infiltration ( $\uparrow$ Arrows in $B$ ) and increase in connective tissue ( $\uparrow$ Arrows in C) are noted (X 160, Hematoxylin-Eosin).

Microscopic images of biopsy samples obtained from abdominal incision lines on the 28th postoperative day indicated that findings of inflammation were genernificantly lower mean score for PMNL infiltration, hyperemia, and increase in connective tissue $(\mathrm{P}<0.05$, Table 4 , Figure 4). The score for epithelization was significantly higher in Group B $(\mathrm{P}<0.05)$, and the scores for edema and macrophage infiltration were similar between groups $(\mathrm{P}>$ 0.05) (Table 4 and Figure 4).

\section{Discussion}

The first finding of the current study was that AMCPM for the repair of incisional hernia reduced intraabdominal adhesions and tissue inflammation was less than standard propylene mash repair.

Recent studies have focused on biomaterials used for reconstruction and prevention methods (7-14). The amniotic membrane, with a long-term history of usage in tissue reconstruction is one of the promising materials to be used as an anti-adhesive (15). In this study the researchers studied intra-abdominal adhesions and tissue inflammation and healing, four weeks after abdominal wall repair, by using AM-CPM in comparison to only polypropylene mesh. Results showed that AM provides advantages of decreasing adhesions along with less inflammation and higher epithelization.

Kesting et al. (24) proved that AM is a biocompatible, resorbable surgical patch serving as a mechanically sufficient material for abdominal wall closure in an in vivo rat model. However, there are limited studies on the use of AM in the reconstruction of the abdominal wall, all of which were experimental animal studies with conflicting outcomes $(6,25-27)$. The majority of these studies showed that AM is an effective antiadhesive barrier in polypropylene mesh repair of abdominal wall hernia $(6,25,26)$.

Kesting et al. (28) also showed that abdominal wall closure with cryopreserved AM and polypropylene mesh was associated with significantly lower intra-abdominal adhesion formation. Similarly, Kelekci et al. (29) also reported that $\mathrm{AM}$ is effective for prevention of adhesion formation 


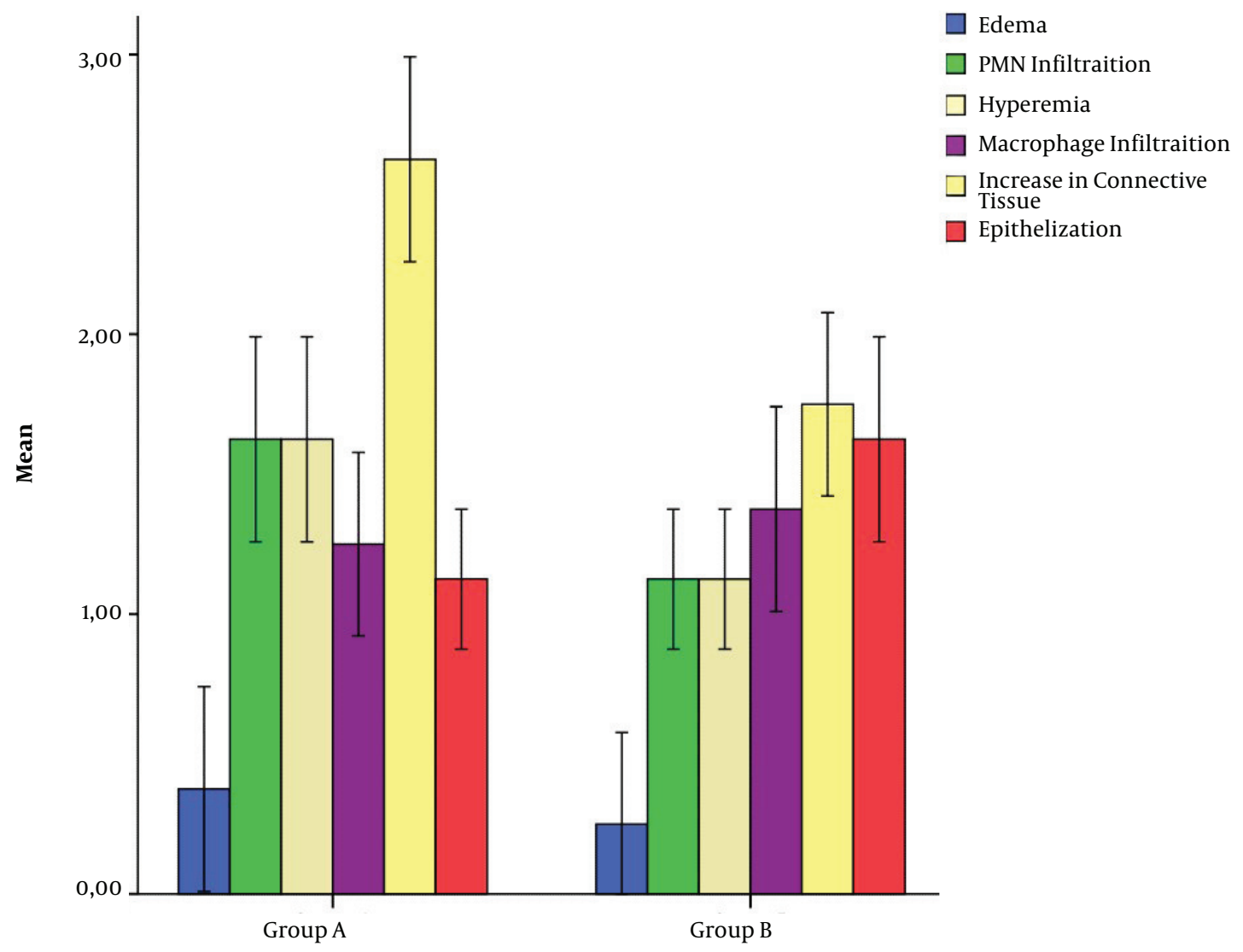

Figure 4. The mean scores for the histopathological assesment of biopsy samples of study groups obtained at postoperative 28th day.

\begin{tabular}{|c|c|c|c|c|}
\hline Grade & \multicolumn{4}{|l|}{ Description of Adhesion Bands } \\
\hline $\mathbf{o}$ & \multicolumn{4}{|l|}{ There is no adhesion. } \\
\hline 1 & \multicolumn{4}{|c|}{ Availability of only one adhesion band between organs or between the organ and abdominal wall } \\
\hline 2 & \multicolumn{4}{|c|}{ Availability of two bands between organs or between the organ and abdominal wall } \\
\hline 3 & \multicolumn{4}{|c|}{$\begin{array}{l}\text { Availability of more than two bands between organs or between the organ and abdominal wall or formation of mass by all intestines without adhesion to the } \\
\text { abdominal wall }\end{array}$} \\
\hline 4 & \multicolumn{4}{|c|}{ Adhesion of an organ to the abdominal wall without considering the number and prevalence of adhesion bands } \\
\hline \multicolumn{5}{|c|}{ Table 2. Nair's Scoring of Study Groups } \\
\hline \multicolumn{2}{|c|}{$\begin{array}{l}\text { Nair's Scoring for Intra-Abdominal Ad- } \\
\text { hesions }\end{array}$} & Group A (Control Group) $n=8$ & Group B (Experimental Group) $n=8$ & $\mathbf{P}^{\mathbf{a}}$ \\
\hline \multicolumn{2}{|c|}{$0-1$ (no or mild adhesion) } & $2(25.0 \%)$ & $6(75.0 \%)$ & \multirow{2}{*}{0.046} \\
\hline \multicolumn{2}{|c|}{ 2- 4 (moderate to severe adhesion) } & $6(75.0 \%)$ & $2(25.0 \%)$ & \\
\hline
\end{tabular}

${ }^{\mathrm{a}}$ Chi-square test. $\mathrm{P}<0.05$ was considered significant.

in a rat uterine horn model. In a recent study by Barbuto et al. (26), AM-CPM was compared to the application of 


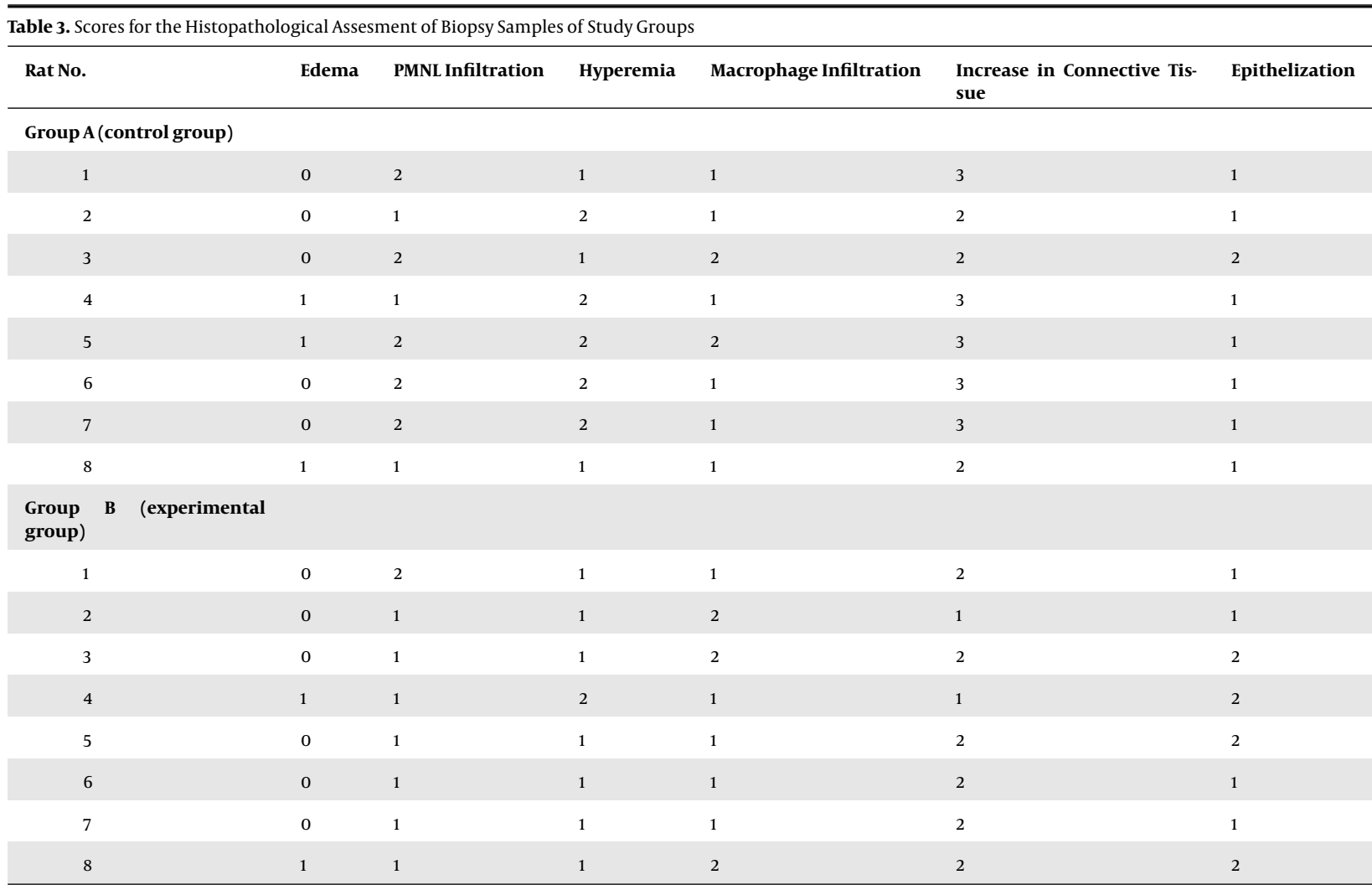

Abbreviation: PMNL, Polymorphonuclear Leukocytes.

Table 4. The Mean \pm SD. (Median, Mode) Scores for the Histopathological Assesment of Biopsy Samples of Study Groups

\begin{tabular}{llll}
\hline & Group A (Control Group) $\mathbf{n}=\mathbf{8}$ & Group B (Experimental Group) $\mathbf{n}=\mathbf{8}$ & $\mathbf{P}^{\mathbf{a}}$ \\
\hline Edema & $0.38 \pm 0.52(0,0)$ & $0.25 \pm 0.46(0,0)$ & 0.590 \\
PMNL infiltration & $1.63 \pm 0.52(2,2)$ & $1.13 \pm 0.35(1,1)$ & 0.039 \\
Hyperemia & $1.63 \pm 0.52(2,2)$ & $1.13 \pm 0.35(1,1)$ & 0.039 \\
Macrophage infiltration & $1.25 \pm 0.46(1,1)$ & $1.38 \pm 0.52(1,1)$ & $1.75 \pm 0.46(2,2)$ \\
\hline Increase in connective tisse & $2.63 \pm 0.52(3,3)$ & $1.63 \pm 0.52(2,2)$ \\
\hline Epithelization & $1.13 \pm 0.35(1,1)$ & 0.018 \\
\hline
\end{tabular}

${ }^{a}$ Chi-square test. $\mathrm{P}<0.05$ was considered significant.

polypropylene mesh alone for the correction of abdominal wall defect in rats. It was found that although AM application did not alter the formation of adhesions after the first week of operation, it accelerated the healing as shown by increased inflammation and angiogenesis activity. In the present study, it was found that AM-CPM was associated with significantly less intra-abdominal adhesions compared to the control group, according to Nair's scoring system, which is a finding consistent with most previous experimental studies.

In addition to the evaluation of post-operative intraabdominal adhesions, this study also assessed the inflam- matory and healing process around the incisional line histopathologically. Overall, the findings indicated that the experimental group (AM-CPM) had lower inflammation, but higher epithelization than the control group (polypropylene mesh). This finding shows that AM-CPM is advantageous over polypropylene mesh alone in terms of tissue healing.

The limitations of the study were its experimental design on a rat model and usage of fresh amniotic membrane. Further clinical studies should be conducted in order to confirm the study findings and to prove the clinical effectiveness of AM as an anti-adhesive barrier so that it can 
be used in routine abdominal surgery. Furthermore, it is difficult to find fresh AM in clinical practice, thus whether preserved AM is as effective as the fresh one should be investigated.

In conclusion, AM-CPM usage in the repair of abdominal wall defects decreases postoperative intra-abdominal adhesions. It is also associated with less inflammation and higher epithelization in incisional area compared to the use of polypropylene mesh alone.

\section{Acknowledgments}

The authors declare that this study received no financial support.

\section{Footnote}

Conflict of Interest: The authors declare no conflict of interest for this article.

\section{References}

1. O'Dwyer PJ, Courtney CA. Factors involved in abdominal wall closure and subsequent incisional hernia. Surgeon. 2003;1(1):17-22. [PubMed: 15568420].

2. Le Huu Nho R, Mege D, Ouaissi M, Sielezneff I, Sastre B. Incidence and prevention of ventral incisional hernia. J Visc Surg. 2012;149(5 Suppl):e3-14. doi: 10.1016/j.jviscsurg.2012.05.004. [PubMed: 23142402].

3. Deerenberg EB, Timmermans L, Hogerzeil DP, Slieker JC, Eilers PH, Jeekel J, et al. A systematic review of the surgical treatment of large incisional hernia. Hernia. 2015;9:89-101.

4. Vorst AL, Kaoutzanis C, Carbonell AM, Franz MG. Evolution and advances in laparoscopic ventral and incisional hernia repair. World J Gastrointest Surg. 2015;7(11):293-305. doi: 10.4240/wjgs.v7.i11.293. [PubMed: 26649152]. [PubMed Central: PMC4663383].

5. Kingsnorth A. The management of incisional hernia. Ann R Coll Surg Engl. 2006;88(3):252-60. doi: 10.1308/003588406X106324. [PubMed: 16719992]. [PubMed Central: PMC1963672].

6. Di Loreto FP, Mangione A, Palmisano E, Cerda JI, Dominguez MJ, Ponce $\mathrm{G}$, et al. Dried human amniotic membrane as an antiadherent layer for intraperitoneal placing of polypropylene mesh in rats. Surg Endosc. 2013;27(4):1435-40. doi: 10.1007/s00464-012-2604-x. [PubMed: 23392973].

7. Hooker GD, Taylor BM, Driman DK. Prevention of adhesion formation with use of sodium hyaluronate-based bioresorbable membrane in a rat model of ventral hernia repair with polypropylene mesh-a randomized, controlled study. Surgery. 1999;125:211-16.

8. Baptista ML, Bonsack ME, Delaney JP. Seprafilm reduces adhesions to polypropylene mesh. Surgery. 2000;128(1):86-92. doi: 10.1067/msy.2000.106810. [PubMed: 10876190].

9. Butler CE, Prieto VG. Reduction of adhesions with composite AlloDerm/polypropylene mesh implants for abdominal wall reconstruction. Plast Reconstr Surg. 2004;114(2):464-73. [PubMed: 15277815].

10. Ricciardi BF, Chequim LH, Gama RR, Hassegawa L. Abdominal hernia repair with mesh surrounded by fibrous tissue: experimental study in Wistar rats. Rev Col Bras Cir. 2012;39:195-200.
11. Mutlu AE, Boztosun A, Sumer D, Yanik A. Comparison of efficiency of clexane "enoxaparin sodium" and methylene blue in prevention of adhesions after cesarean section in pregnant rats. JTurk Soc Obstet Gynecol. 2012;9:216-23.

12. Yașar, M, Ice, Z, Ozaydın, I . The effect of strech film and prolen mesh usage on adhesion for closure of abdominal wall defects: experimental study. Med J Kocaeli. 2012;1(12-6).

13. Sorour MA. Interposition of the omentum and/or the peritoneum in the emergency repair of large ventral hernias with polypropylene mesh. Int J Surg. 2014;12(6):578-86. doi:10.1016/j.ijsu.2014.04.009. [PubMed: 24793234].

14. Jayanth ST, Pulimood A, Abraham D, Rajaram A, Paul MJ, Nair A. A randomized controlled experimental study comparing chitosan coated polypropylene mesh and Proceed mesh for abdominal wall defect closure. Ann Med Surg (Lond). 2015;4(4):388-94. doi: 10.1016/j.amsu.2015.10.002. [PubMed: 26594357]. [PubMed Central: PMC4610956].

15. Favaron PO, Carvalho RC, Borghesi J, Anunciacao AR, Miglino MA. The Amniotic Membrane: Development and Potential Applications - A Review. Reprod Domest Anim. 2015;50(6):881-92. doi: 10.1111/rda.12633. [PubMed: 26510939].

16. Farghali HA, AbdElKader NA, Khattab MS, AbuBakr HO. Novel approach to gastric mucosal defect repair using fresh amniotic membrane allograft in dogs (experimental study). Stem Cell Res Ther. 2017;8(1):235. doi: 10.1186/s13287-017-0682-3. [PubMed: 29047409]. [PubMed Central: PMC5648434].

17. Gheorghe A, Pop M, Burcea M, Serban M. New clinical application of amniotic membrane transplant for ocular surface disease. J Med Life. 2016;9(2):177-9. [PubMed: 27453750]. [PubMed Central: PMC4863510].

18. Mohan R, Bajaj A, Gundappa M. Human Amnion Membrane: Potential Applications in Oral and Periodontal Field. J Int Soc Prev Community Dent. 2017;7(1):15-21. doi: 10.4103/jispcd.JISPCD_359_16. [PubMed: 28316944]. [PubMed Central: PMC5343678].

19. Cirman T, Beltram M, Schollmayer P, Rozman P, Kreft ME. Amniotic membrane properties and current practice of amniotic membrane use in ophthalmology in Slovenia. Cell Tissue Bank. 2014;15(2):177-92. doi: 10.1007/s10561-013-9417-6. [PubMed: 24352631].

20. Jain A, Jaiswal GR, Kumathalli K, Kumar R, Singh A, Sarwan A. Comparative Evaluation of Platelet Rich Fibrin and Dehydrated Amniotic Membrane for the Treatment of Gingival Recession- A Clinical Study.J Clin Diagn Res. 2017;11(8):ZC24-8. doi: 10.7860/JCDR/2017/29599.10362. [PubMed: 28969268]. [PubMed Central: PMC5620915].

21. Robin C, Bollerot K, Mendes S, Haak E, Crisan M, Cerisoli F, et al. Human placenta is a potent hematopoietic niche containing hematopoietic stem and progenitor cells throughout development. Cell Stem Cell. 2009;5(4):385-95. doi: 10.1016/j.stem.2009.08.020. [PubMed: 19796619]. [PubMed Central: PMC2812802].

22. Seifeldin A. Vaginal wall repair using amniotic membrane graft. $\mathrm{Ob}$ stet Gynecol Int J. 2015;2(5):56.

23. Nair SK, Bhat IK, Aurora AL. Role of proteolytic enzyme in the prevention of postoperative intraperitoneal adhesions. Arch Surg. 1974;108(6):849-53. [PubMed: 4829809].

24. Kesting MR, Wolff KD, Mucke T, Demtroeder C, Kreutzer K, Schulte $\mathrm{M}$, et al. A bioartificial surgical patch from multilayered human amniotic membrane-In vivo investigations in a rat model. J Biomed Mater Res B Appl Biomater. 2009;90(2):930-8. doi: 10.1002/jbm.b.31365. [PubMed: 19441115].

25. Szabo A, Haj M, Waxsman I, Eitan A. Evaluation of seprafilm and amniotic membrane as adhesion prophylaxis in mesh repair of abdominal wall hernia in rats. Eur Surg Res. 2000;32(2):125-8. doi: 10.1159/000008751. [PubMed: 10810219].

26. Barbuto RC, de Araujo ID, Bonomi Dde O, Tafuri LS, Calvao Neto A, Malinowski R, et al. Use of the amniotic membrane to cover the peritoneal cavity in the reconstruction of the abdominal wall with polypropylene mesh in rats. Rev Col Bras Cir. 2015;42(1):49-55. doi: 10.1590/010069912015001010. [PubMed: 25992701]. 
27. Zawaneh PN, Putnam D. Materials in surgery: a review of biomaterials in postsurgical tissue adhesion and seroma prevention. Tissue Eng Part B Rev. 2008;14(4):377-91. doi: 10.1089/ten.teb.2008.0226. [PubMed: 18816187].

28. Kesting MR, Loeffelbein DJ, Steinstraesser L, Muecke T, Demtroeder $\mathrm{C}$, Sommerer F, et al. Cryopreserved human amniotic membrane for soft tissue repair in rats. Ann Plast Surg. 2008;60(6):684-91. doi:
10.1097/SAP.ob013e31814fb9d2. [PubMed: 18520208].

29. Kelekci S, Uygur D, Yilmaz B, Sut N, Yesildaglar N. Comparison of human amniotic membrane and hyaluronate/carboxymethylcellulose membrane for prevention of adhesion formation in rats. Arch Gynecol Obstet. 2007;276(4):355-9. doi: 10.1007/s00404-007-0376-7. [PubMed: 17492299]. 